\section{Psychiatric consequences of nitrous oxide abuse}

We would like to describe the case of a patient we treated who developed neuropsychiatric symptoms secondary to recreational use of nitrous oxide $\left(\mathrm{N}_{2} \mathrm{O}\right)$.

Mr. N, a 24-year-old military veteran, presented to the emergency department (ED) with symptoms of numbness, tingling of his entire body, and difficulty walking for the past 3 days. His family recently became concerned when they noted changes in his personality and behavior, including increased irritability, verbal aggression, and paranoia. The family reported that before the recent changes, Mr. $\mathrm{N}$ had typically been calm and had a pleasant temperament. When Mr. N's symptoms progressed to difficulty ambulating, his family brought him to the ED for evaluation.

During his interview, Mr. N reported that he started using $\mathrm{N}_{2} \mathrm{O} 2$ years ago for recreational purposes because he learned it is legal to purchase and undetectable on a urine drug screen. He said he had been using $>100$ $\mathrm{N}_{2} \mathrm{O}$ canisters per day and had spent approximately $\$ 15,000$ over the past few months. His use had increasingly escalated up to 3 days before his visit to the $\mathrm{ED}$, which was the last day he used $\mathrm{N}_{2} \mathrm{O}$.

\section{Keep in touch!}

letters@currentpsychiatry.com

OR

Comments \& Controversies

CURRENT PSYCHIATRY

7 Century Drive, Suite 302

Parsippany, NJ 07054

All letters are subject to editing.
Mr. $\mathrm{N}$ was admitted to the inpatient medical service. Laboratory testing revealed a low-normal vitamin B12 level of $254 \mathrm{pg} / \mathrm{mL}$ (normal range: 200 to $900 \mathrm{pg} / \mathrm{mL}$ ), an elevated methylmalonic acid blood level of 2,491 nmol/L (normal range: 73 to $376 \mathrm{nmol} / \mathrm{L}$ ), and an elevated homocysteine blood level of $22.4 \mu \mathrm{mol} / \mathrm{L}$ (normal range: 0 to $15 \mu \mathrm{mol} / \mathrm{L}$ ). Magnetic resonance imaging studies showed hyperintensity regions on his cervical spine from the $\mathrm{C} 1$ to $\mathrm{C} 6$ levels. These changes suggested demyelination due to vitamin B12 deficiency from $\mathrm{N}_{2} \mathrm{O}$ abuse.

Mr. N was started on vitamin B12 injections and physical therapy, which led to the resolution of his concerning neurologic symptoms. A few weeks after admission, he was discharged with outpatient follow-up services. Unfortunately, he was lost to follow-up.

Approximately 1 year later, Mr. N returned to the ED with anxiety and paranoid ideation. Medical workup at the time was normal (including vitamin B12 and methylmalonic acid blood levels). He denied any recent substance use and was admitted voluntarily to the psychiatric unit. He declined the recommended treatment of risperidone. Because he showed no signs or symptoms that warranted involuntary retention, he was discharged. Over the next few months, he had 4 visits to the ED with similar concerns and poor adherence to outpatient treatment.

On Mr. N's fourth admission, he agreed to a course of long-acting injectable paliperidone and escitalopram to target his psychotic and anxious symptoms. These treatments stabilized him, and he was discharged.
Neuropsychological testing later showed impairment across several cognitive domains, including memory, processing speed, attention, and executive functioning.

Identifying $\mathrm{N}_{2} \mathrm{O}$ use. $\mathrm{N}_{2} \mathrm{O}$ is not detected on routine drug screen panels. Obtaining a careful psychiatric and substance use history, as well as conducting a neurologic assessment, are helpful to identify $\mathrm{N}_{2} \mathrm{O}$ use. Both acute and chronic inhalation of $\mathrm{N}_{2} \mathrm{O}$ can result in vitamin B12 deficiency with hematologic (megaloblastic anemia), neurologic (subacute combined degeneration of spinal cord, motor-sensory polyneuropathy), and psychiatric sequelae (memory loss, depression, hypomania, transient psychosis). ${ }^{1}$ Patients who exhibit these changes warrant workup for vitamin B12 deficiency, which includes testing for B12, homocysteine, and methylmalonic acid blood levels. Magnetic resonance imaging should be considered for patients who exhibit neurologic symptoms.

The means by which $\mathrm{N}_{2} \mathrm{O}$ causes neuropsychiatric changes have been explored in the literature. There is general consensus that part of $\mathrm{N}_{2} \mathrm{O}^{\prime}$ s deleterious effects is due to the inactivation of vitamin B12 by the irreversible oxidation of $\mathrm{Cob}(\mathrm{I})$ alamin to $\mathrm{Cob}(\mathrm{III})$ alamin. ${ }^{1}$

Treatment. The recommended treatment is high-dose oral or parenteral vitamin B12. ${ }^{1}$ Repletion of vitamin B12 is believed to reverse the course of illness. However, our patient's symptoms of paranoia and delusions persisted despite resolution of his neurologic symptoms after the underlying vitamin B12 deficiency was corrected.

continued 
Due to $\mathrm{N}_{2} \mathrm{O}^{\prime}$ s wide availability and growing recreational use, it is important for clinicians to ask their patients about their use of this substance. The abuse of $\mathrm{N}_{2} \mathrm{O}$ remains an important topic that requires further research, particularly in adolescents, who are still undergoing significant brain development. ${ }^{2,3}$

Daniel Roberts, MD, MSW

PGY-3 Psychiatric Resident Department of Psychiatry New York University Grossman School of Medicine New York, New York
Pantea Farahmand, MA, MD Assistant Professor

Department of Psychiatry New York University Grossman School of Medicine Inpatient Psychiatrist

Veterans Administration New York Harbor Healthcare System New York, New York

Adam Wolkin, MD

Associate Professor and Vice Chair New York University Grossman School of Medicine Associate Chief of Staff for Mental Health Veterans Administration New York Harbor Healthcare System New York, New York
Disclosures: The authors report no financial relationships with any companies whose products are mentioned in this article, or with manufacturers of competing products.

\section{References}

1. Thompson AG, Leite MI, Lunn MP, et al. Whippits, nitrous oxide and the dangers of legal highs. Pract Neurol. 2015;15(3):207-209.

2. Global Drug Survey 2017. Global Drug Survey. Published May 24, 2017. Accessed January 12, 2021. https://www.globaldrugsurvey. com/past-findings/gds2017-launch/resultsreleased/

3. Kaar SJ, Ferris J, Waldron J, et al. Up: the rise of nitrous oxide abuse. An international survey of contemporary nitrous oxide use. J Psychopharmacol. 2016;30(4):395-401.

doi: $10.12788 /$ cp.0097 